\title{
KEGIATAN JENAYAH DI KEDAH MENERUSI SURAT-MENYURAT SULTAN ABDUL HAMID (SMSAH)
}

\author{
Mohd Kasturi Nor bin Abd Aziz
}

\begin{abstract}
This article discusses social issues that occurred in Kedah through an examination of the collection of letters of Sultan Abdul Hamid (SMSAH) which are related to robberies, theft, homicide, injury inflictment on individuals, fenale abductions and the inoolvement of high-ranking managentent officers in crime. These criminal actiotitis had a negative influence on the socio-economic development and political stability in Kedah. These social issues had drawn the attention of Kedah's govennent under the leadership of Sultan Abdul Hamid with the aid of his local officials who later took several steps to reduce the crinte rate by enforcing lans, cooperating with the British as well as the Siamese and the formation of a police force. Based on the collection of letters of Sultan Abdul Hamid and some Kedah Annual Report, this study shows that social issues were a serious concern in Kedah during the reign of Sultan Abdul Hamid.
\end{abstract}

\section{Pengenalan}

Koleksi Surat-Menyurat Abdul Hamid (SMSAH) yang kini berada dalam simpanan Árkib Negara Malaysia cawangan Kedah/Perlis dan lbu Pejabat Arkib Negara Malaysia Kuala Lumpur merupakan sebuah himpunan warkah diraja Melayu yang ditulis semasa zaman Sultan Abdul Hamid Halim Shah, Sultan Kedah yang ke-25 (1882-1943) dalam bentuk tulisan jawi dengan menggunakan tulisan tangan. Jika berdasarkan koleksi SMSAH yang tersimpan di Arkib Negara Malaysia cawangan Kedah/Perlis buat masa ini didapati berjumlah 16 buah 
naskhah. Dua buah naskhah SMSAH yang terakhir mengandungi beberapa pucuk surat Sultan Ahmad Tajuddin Shah dan surat Sultan Abdul Hamid.

Koleksi SMSAH ini telah diiktiraf dan diwartakan sebagai warisan dunia atau "Memory of the World Register" pada September 2001 oleh pihak United Nation Educational, Scientific and Cultural Organization (UNESCO) atas hasil usaha Arkib Negara Malaysia dengan kerjasama para penyelidik tempatan. Pengiktirafan ini juga diberikan kerana keunikan yang terdapat pada koleksi SMSAH ini sebagai satu-satunya rekod bertulis mengenai Kesultanan Melayu semasa zaman penjajahan kuasa asing yang masih dipelihara sehingga kini. SMSAH ini mengandungi banyak maklumat mengenai sejarah negeri Kedah sewaktu peralihan kuasa Siam dan kemasukan British dalam pentadbirannya.

\section{Latar Belakang Sultan Abdul Hamid Halim Shah}

Sultan Abdul Hamid Halim Shah telah diputerakan pada 4 Jun 1864. Ayah baginda ialah Almarhum Sultan Ahmad Tajuddin Mukarram Shah III (1854-1879) dan ibunya pula bernama Wan Hajar Wan Ismail. ${ }^{1}$ Baginda ialah Sultan Kedah yang ke-25 y ang memerintah dari tahun 1882 sehingga 1943. Baginda menaiki takhta sebagai Sultan Kedah pada 21 Januari 1882 ketika baginda berusia 19 tahun. Menandangkan usia baginda masih muda ketika ditabalkan, Jemaah Pemangku Raja telah dilantik untuk membantu baginda dalam urusan pemerintahan dan pentadbiran negeri. Sepanjang pemerintahan, baginda telah membawa perubahan dari aspek ekonomi, politik dan sosial dalam usaha memodenkan Kedah pada sekitar aw al abad ke-20.2 Pada ketika itu, Kedah sedang menghadapi asakan dan campur tangan daripada kuasa Siam dan British dalam urusan politik.

Kejayaan Sultan Abdul Hamid dalam memajukan Kedah pada akhir abad ke-19 sehingga awal abad ke-20 banyak dibantu oleh sokongan dan kerjasama para kerabat diraja dan pembesar negeri seperti Dato' Wan Muhammad Saman (Perdana Menteri Kedah yang pertama), Tunku Ibrahim, Tunku Abdul Aziz (Raja Muda Kedah), Haji Ahmad (Hakim Besar) dan Cik Mohamed Ariffin (Setiausaha Kerajaan). ${ }^{3}$ Namun pada penghujung pemerintahan, Sultan Abdul Hamid telah kehilangan ramai kaum kerabat diraja dan pembesar kerajaan yang berwibawa dan taat setia selama ini banyak membantu baginda dalam urusan pentadbiran Kedah. Ini telah menyebabkan urusan kerajaan terganggu dan baginda tidak mendapat khidmat nasihat bagi menghadapi campur tangan British di Kedah. Tambahan pula, baginda sendiri sering mengalami masalah kesihatan yang jelas menjejaskan kemampuannya 
dalam menjalankan tugas rasmi. Situasi ini membolehkan kuasa British mencampuri urusan kerajaan Kedah sewenang-wenangnya tanpa perlu rasa bimbang. Walau bagaimanapun, Sultan Abdul Hamid masih dianggap sebagai seorang pemerintah Melayu yang memiliki kebesaran daulat yang diakui oleh lapisan masyarakat dan generasi di mana potret baginda sering ditemui di premis-premis sekitar negeri Kedah, Pulau Pinang dan Perak dan masih dipamerkan sehingga hari ini atas anggapan ia sebagai pelaris jualan atau sebagai kenangan dan kebanggaan dengan kesolehan baginda semasa hidup. ${ }^{4}$

Berdasarkan penelitian khusus terhadap SMSAH, didapati terkandung banyak maklumat penting mengenai kegiatan jenayah yang berlaku di Kedah semasa zaman Sultan Abdul Hamid dalam pelbagai bentuk seperti surat, catatan dan laporan. Berbanding dengan Kedah Annual Report (KAR), maklumat mengenai kegiatan jenayah hanya dilaporkan pada tahun 1905 ke atas, di mana ia dikeluarkan oleh pihak British dan ini bermaksud kegiatan jenayah di Kedah sebelum 1905 tidak dikupas dalam KAR dan ia hanya ditemui dalam SMSAH sahaja. Malah, peranan yang dimainkan oleh Sultan Abdul Hamid dan para pembesar negeri dalam usaha menangani kegiatan jenayah juga kurang ditonjolkan dalam KAR. Perkara ini menjadikan SMSAH sebagai sumber penting dalam kajian pensejarahan Kedah semasa zaman pemerintahan Sultan Abdul Hamid khususnya berkaitan dengan kegiatan jenayah dan tindakan menanganinya oleh kerajaan Kedah.

\section{Kegiatan Jenayah di Kedah}

Maklumat-maklumat tentang hal ehwal sosial negeri Kedah yang terkandung dalam SMSAH banyak berkisar kepada beberapa kejadian yang berlaku ke atas rakyat Kedah, Pulau Pinang, selatan Siam dan Perak, terutamanya berhubung dengan pelbagai kesalahan jenayah. Perbuatan jenayah banyak dicatat dalam SMSAH No. 2, 3, 5, 10. Manakala dalam SMSAH No. 11, 12 dan 13 pula menyentuh beberapa rang undangundang yang telah diluluskan oleh Majlis Mesyuarat Negeri Kedah bagi membanteras perbuatan jenayah berkenaan. Menyentuh tentang hubungan antara kerajaan Kedah dengan pihak Siam, British dan Perak bukan sahaja dalam bidang diplomatik semata-mata malah membabitkan hubungan sosial termasuk kes-kes jenayah yang berlaku dan tindakan yang diambil oleh pihak berkuasa di wilayah masingmasing. Perbuatan jenayah yang berleluasa di Kedah dari sempadan Siam hingga ke Province Wellesley juga amat membimbangkan ramai pihak terutamanya pihak British. Antara perbuatan jenayah yang kerap dilaporkan seperti samun, mencuri, penipuan, perbuatan membunuh 
dan mencederakan individu, melarikan perempuan tanpa kebenaran, pergaduhan dan pembabitan golongan pentadbir dalam jenayah. ${ }^{5}$

\section{Kegiatan Menyamun}

Perbuatan jenayah telah dilaporkan dalam sepucuk surat Sultan Abdul Hamid kepada pihak Setul mengenai kegiatan samun yang telah dilakukan oleh beberapa orang Cina di Sungai Upeh, wilayah Setul bertarikh 19 Januari 1888. Isi kandungan surat itu juga menyentuh tentang tindakan pihak Kedah membuat siasatan lanjut mengenai perbuatan jenayah berkenaan dan perkara ini telah dilaporkan kepada pihak Siam. ${ }^{6}$ Selain itu, kegiatan menyamun yang dilakukan oleh orang Cina di Pulau Ipoh turut dicatat dan satu siasatan terperinci telah dibuat. Pihak Kedah telah memberi kerjasama kepada pihak Siam untuk menangkap penjenayah berkenaan.'

Satu laporan mengenai kegiatan menyamun yang dilakukan oleh sekumpulan penjenayah berbangsa Melayu di Sungai Kerian telah dihantar kepada Konsul Siam di Pulau Pinang untuk tindakan selanjutnya, selepas Sultan Abdul Hamid menerima surat aduan daripada Residen Inggeris di Perak pada 24 November $1882 .{ }^{8}$ Pihak Kedah juga turut memberi kerjasama kepada pihak Perak dalam usaha menangkap ahli kumpulan perompak berkenaan tetapi gagal. Kumpulan berkenaan dipercayai telah melarikan diri ke Betong dalam wilayah Pattani. Sultan Abdul Hamid pernah memohon bantuan Raja Reman yang memerintah wilayah berkenaan bagi menangkap ahli kumpulan berkenaan. Berpandukan siasatan yang dijalankan oleh Haji Ali (wakil Kedah yang ditugaskan menjaga kawasan Kerian), pihak Kedah berjaya menjejaki kesan yang ditinggalkan oleh penyamun berkenaan yang berupa beberapa helai pakaian. Walaupun gagal menangkap ahli kumpulan samun berkenaan, pihak Kedah telah bertindak menahan isteri-isteri mereka untuk disoal siasat.

Sultan Abdul Hamid turut meminta bantuan dari pihak Singgora bagi menangkap penjenayah yang menyamun di Kedah dan kemudiannya melarikan diri ke wilayah berkenaan. Di dalam surat bertarikh 25 Disember 1888, baginda telah menyenaraikan barang yang disamun daripada Ah See. ${ }^{9}$ Selain kes berkenaan, pihak Kedah juga turut meminta bantuan daripada kerajaan Singgora untuk menangkap kumpulan penyamun yang telah memecah masuk dan melarikan harta milik Lebai Hasan dan Ismail di Mukim Pedu ke Chani dan disertakan dengan lampiran nama-nama penyamun berkenaan pada tahun 1888 . Pihak Singgora juga pernah meminta bantuan daripada kerajaan Kedah bagi menangkap penyamun yang berjaya memecah masuk rumah 
Alang Lubuk dan Mat Salleh Gendang yang menyebabkan pemiliknya menanggung kerugian yang agak besar. ${ }^{10}$

Seringkali pesalah yang telah dijatuhi hukuman, membuat rayuan di mahkamah dengan meminta diringankan hukuman atau diampunkan. Sebagai contoh, seorang individu bernama Mohammad bin Haji Bakar telah dijatuhkan hukuman penjara lapan tahun kerana terlibat dalam kegiatan menyamun pada tahun 1926, telah merayu agar diampunkan dari kesalahan berkenaan. ${ }^{11}$ Malah kegiatan menyamun turut melibatkan bekas anggota polis yang melakukannya di salah satu kelab candu yang terdapat di Kedah. ${ }^{2}$ Perbuatan menyamun ini begitu berleluasa dan membimbangkan ramai pihak kerana ia cepat merebak ke seluruh negeri Kedah. Malah kegiatan menyamun ini turut dikaitkan dengan kegiatan kongsi gelap. ${ }^{13}$ Perkara ini turut diberi perhatian serius oleh Sultan Abdul Hamid. Baginda telah mengesa satu tindakan dan hukuman yang tegas perlu diambil dan kerjasama antara Kedah dengan Siam dan British juga harus diperkukuhkan dalam usaha menangani kegiatan tersebut. Tindakan ini ditonjolkan dalam SMSAH dan membuktikan pejabat sultan memainkan peranan penting dalam mengawal hal-ehwal dalaman negeri Kedah, termasuk tindakan tegas membanteras kegiatan jenayah seperti menyamun, walaupun memerlukan bantuan dan kerjasama daripada kuasa asing seperti pihak British dan Siam.

\section{Mencuri Harta dan Ternakan}

Perbuatan jenayah mencuri binatang ternakan seperti kerbau dan lembu turut dicatat dalam SMSAH. Kegiatan jenayah yang berleluasa di Kedah amat dibimbangi mengancam nyawa dan kehilangan harta benda penduduk. Sebelum ini kerajaan Kedah juga kerap diberi peringatan oleh pihak British agar sentiasa menjaga keamanan dan berusaha menyekat sebarang kegiatan jenayah dari merebak ke wilayahnya, kerana kumpulan penjenayah sering mengganggu dan mengganas di sempadan kedua-dua wilayah dan bergerak secara bebas tanpa sekatan. Malah, mereka juga dapat melarikan diri dengan mudah ke Kedah dan Perak yang bersempadan dengan Province Wellesley dan ini menyukarkan pihak polis untuk menangkap dan membanteras kegiatan berkenaan. ${ }^{14}$ Baginda juga pernah mengutuskan sepucuk surat kepada Raja Singgora mengenai aduan kehilangan dua belas ekor kerbau milik Hamid di Kedah yang dipercayai telah dicuri oleh beberapa orang suspek berbangsa Siam. Walau bagaimanapun, kerbau berkenaan telah berjaya dijumpai dan suspek berkenaan telah ditahan serta diambil keterangannya sebelum dibenarkan pulang ke Singgora. ${ }^{15}$ Kes kecurian binatang ternakan sering dilaporkan berlaku 
di wilayah Kedah-Singgora. ${ }^{16}$ Bagi mengatasi masalah penyeludupan dan mencuri binatang ternakan yang berleluasa di kawasan sempadan Kedah-Siam, Sultan Abdul Hamid telah mencadangkan kepada Raja Singgora agar diwujudkan pas keluar-masuk bagi kerbau dan lembu dari wilayah masing-masing. ${ }^{77}$ Berdasarkan laporan mengenai kegiatan mencuri binatang ternakan di dalam SMSAH didapati kerajaan Kedah berusaha menangani kegiatan jenayah yang berlaku dengan bantuan para pembesar tempatan, anggota keselamatan dan rakyat jelata.

Merujuk laporan rasmi, Kedah Utara seperti daerah Changloon dilaporkan sering berlaku kejadian mencuri lembu yang membabitkan penjenayah berbangsa Melayu.$^{18}$ Seringkali, binatang ternakan seperti lembu dan kerbau yang dicuri di kawasan Kedah Utara diseludup ke wilayah Siam untuk dijual atau disembelih. ${ }^{19}$ Kadangkala, pihak penjenayah juga mengambil kesempatan daripada kehilangan lembu berkenaan dengan menuntut wang tebusan daripada tuan punya lembu berkenaan. Selain itu, masalah kawalan di sempadan Kedah-Siam yang longgar membolehkan pihak penjenayah bebas keluar masuk. Kerajaan Kedah juga memandang serius kesalahan mencuri dan menyeludup binatang ternakan secara haram kerana ia menyebabkan pemilik binatang ternakan mengalami kerugian yang besar. Perkara ini jelas ditunjukkan dalam SMSAH malah disokong oleh sumber-sumber pihak British dan Siam.

Perbuatan jenayah seperti mencuri wang dan barangan individu lain turut dicatat dalam SMSAH. Turut termuat dalam himpunan surat ini ialah surat balasan baginda kepada Leftenan Gabernor Pulau Pinang, mengenai aduan ke atas Muhammad Hussein yang telah melakukan kesalahan pecah amanah dan melarikan wang milik Tuan Fedricks, seorang pegawai syarikat milik British, berjumlah 2500 rial pada 15 Julai $1882 \mathrm{M} .{ }^{20}$ Sultan Abdul Hamid turut berhubung dengan Residen British di Perak tentang perbuatan beberapa orang pekerja Dato' Wan Muhammad Saman, yang telah melarikan barang-barang penting milik majikannya dan kemudiannya berjaya ditangkap dan dibicarakan di Perak. Residen British di Perak juga memohon kerjasama daripada baginda untuk menghantar saksi penting untuk membantu siasatan kes berkenaan. Permintaan beliau itu telah dipenuhi oleh baginda dengan menghantar dua orang saksi. Dalam surat yang sama, Sultan Abdul Hamid meminta jasa baik Residen dapat menyiasat dengan lebih teliti agar tidak timbul unsur penganiayaan ke atas pihak yang terbabit. ${ }^{21}$ Perkara ini menunjukkan Sultan Abdul Hamid sentiasa peka dan mengambil berat tentang perkembangan sosial yang berlaku di Kedah termasuk masalah jenayah. Berdasarkan SMSAH juga didapati sultan Kedah begitu mengawal hal-ehwal negeri Kedah dengan dibantu oleh para pembesar tempatan dalam usaha membasmi kegiatan jenayah 
tanpa merosakkan hubungan diplomatik yang telah terjalin antara Kedah dengan pihak British sekitar akhir kurun ke-19 sehingga awal kurun ke-20.

\section{Perbuatan Membunuh dan Mencederakan Individu}

Kesalahan jenayah seperti membunuh dan mencederakan individu lain turut disentuh dalam SMSAH. Antaranya catatan mengenai kes jenayah yang berlaku di Perak ialah sepucuk surat Sultan Abdul Hamid kepada Konsul Siam, mengenai laporan siasatan ke atas Abu Seman yang dituduh membunuh seorang individu berbangsa Cina bernama Chin dari Perak pada $28 \mathrm{Mei} 1882$. Siasatan yang telah dijalankan mendapati ada bukti kukuh yang menunjukkan si tertuduh telah melakukannya. Kes ini telah dbicarakan di Mahkamah Besar Kedah yang dihakimi oleh Tunku Abdullah. Perbicaraan berkenaan telah dihadiri oleh dua orang saksi berbangsa Cina dan Tuan Lech, Majistret British di Kerian. Abu Seman telah didapati bersalah dan dihukum penjara selama 12 tahun serta dikenakan hukuman membuat kerja-kerja berat. Hasil perbicaraan itu juga telah dimaklumkan kepada Raja Muda Perak menerusi surat. ${ }^{22}$

Pihak Kedah juga pernah memohon bantuan daripada Perak dalam usaha menangkap Saad Putih yang dipercayai berada di Perak setelah membunuh dua orang Cina di Kedah. Sultan Abdul Hamid juga pernah memohon jasa baik Raja Yusof untuk menyerahkan pesalah berkenaan untuk dibicarakan di Kedah. Perkara ini juga telah diketahui oleh Residen British di Perak, Sir Hugh Low, yang ketika itu berada di Pulau Pinang. ${ }^{23}$ Di samping itu juga, terdapat beberapa pucuk surat kiriman Sultan Abdul Hamid kepada Residen Perak mengenai permintaan baginda agar diserahkan seorang Cina yang telah membunuh seorang perempuan di Baling, Kedah, kemudiannya telah ditahan di Kubang, Perak. Di dalam surat bertarikh 27 Mei 1891, dilampirkan satu salinan laporan kes berkenaan daripada pihak polis. Sultan Abdul Hamid mengetahui perkara ini setelah diberitahu oleh Konsul Siam di Pulau Pinang yang menerima surat pemberitahuan oleh Residen Perak sebelum ini. Di samping itu, baginda juga memberitahu Konsul Siam mengenai pengiriman surat berkenaan kepada Residen Perak. ${ }^{24}$

Terdapat beberapa pucuk surat dari Sultan Abdul Hamid turut dikirimkan pada Sir Frank Swettenham, Residen Perak, mengenai kenyataan seorang mata-mata gelap Perak yang menggantikan seorang penghulu di kawasan Baling telah melepaskan seorang pesalah. Jika benar kenyataan yang dibuatnya, mereka mesti dikenakan hukuman yang berat. ${ }^{25}$ Malah, baginda ada mengutuskan surat kepada pihak Siam mengenai aduan seorang Cina terhadap Syed Othman yang dikatakan membunuh seorang Cina di Setul dan telah melarikan 
diri ke Phuket. ${ }^{26}$ Berdasarkan catatan dalam SMSAH menunjukkan kejadian pembunuhan di Kedah begitu serius dan sering berlaku. Malah penjenayah yang terbabit sering melarikan diri ke kawasan sempadan Kedah-Siam, Perak dan Pulau Pinang. Ini menunjukkan ada kelemahan dari segi kawalan sempadan yang membolehkan mereka melarikan diri. Walau bagaimanapun, pihak Kedah sentiasa bekerjasama dengan pihak Siam, British dan Perak bagi menangani masalah ini dengan melancarkan operasi memburu dan menangkap penjenayah berkenaan. Maklumat dalam SMSAH ini telah membuktikan Sultan Abdul Hamid dan para pembesar begitu serius dalam usaha membasmi kegiatan jenayah di Kedah khususnya dalam kes pembunuhan.

Selain itu, Sultan Abdul Hamid sering mengutuskan surat kepada pihak Siam mengenai kes pembunuhan dan meminta bantuan untuk menangkap si pembunuh berkenaan yang melarikan diri ke wilayah Siam. ${ }^{2 z}$ Surat daripada para pembesar Kedah mengenai aduan kes pembunuhan juga turut dicatatkan. Antara surat itu adalah mengenai aduan tentang Mat Taib dari Pulau Pinang yang telah membunuh seorang Cina di Permatang Bendahari dan telah ditemui berdekatan dengan air terjun. Penghulu Kuala Muda telah diarahkan menyerahkan pembunuh kepada pihak polis untuk siasatan selanjutnya. ${ }^{28} \mathrm{Kes}$ pembunuhan turut dilaporkan berlaku di Kuala Pegang, Kuala Muda. Pembunuh berkenaan, Lebai Deraman, telah berjaya melarikan diri ke Betong tetapi berjaya ditahan oleh pihak Siam. Kemudiannya penjenayah ini telah diserahkan kepada pihak berkuasa Kedah untuk dihukum. Merujuk kepada surat dalam SMSAH ini menunjukkan wujud kerjasama yang baik di antara pihak Siam dengan kerajaan Kedah dalam usaha menangani masalah jenayah di kawasan masing-masing. Dalam waktu yang sama, sikap hormat-menghormati undang-undang satu sama lain turut ditonjolkan dalam SMSAH melalui perbuatan mengekstradisi beberapa orang penjenayah oleh pihak Siam kepada pihak Kedah. ${ }^{29}$

Terdapat beberapa pucuk surat yang ditulis oleh Tunku Yaakob, ayah saudara baginda dan Raja Muda, Tunku Abdul Aziz dalam SMSAH mengenai hal-hal jenayah. ${ }^{30}$ Sebagai contoh, surat kiriman Raja Muda Kedah kepada Residen Kaunselor British di Pulau Pinang adalah mengenai arahan menyerahkan beberapa pesalah yang bernama Taib dan Meah yang sedang ditahan di Kuala Muda, semasa Sultan Abdul Hamid berangkat ke Rangoon, Burma pada tahun $1892 .{ }^{31} \mathrm{Di}$ samping itu, Che Ariffin Kerani, Setiausaha Sultan pernah mengirimkan surat kepada Wan Yahya Wan Mohd Taib yang bertanggungjawab di Changloon tentang penghantaran 26 pucuk notis mengenai orang-orang yang melakukan kesalahan dalam negeri Kedah. Notis ini juga turut dihantar ke Kuala Muda sebanyak 25 pucuk, Kulim sebanyak 16 pucuk, 
Kerian sebanyak 11 pucuk dan Pulau Langkawi sebanyak 11 pucuk pada tahun 1901. ${ }^{32}$ Perkara ini menunjukkan sistem pentadbiran yang cekap di bawah pemerintahan Sultan Abdul Hamid dengan dibantu pula sistem pengurusan yang begitu sistematik dalam kalangan pembesar tempatan telah banyak menyokong keutuhan kerajaan Kedah, termasuk usaha menangani kegiatan jenayah, suatu hal yang kurang ditonjolkan dalam laporan tahunan Kedah yang diterajui oleh Penasihat British , sebaliknya begitu ketara dalam SMSAH. ${ }^{33}$

\section{Laporan Penipuan}

Laporan mengenai penipuan yang melibatkan individu tertentu juga turut disentuh dalam SMSAH. Perbuatan ini juga kerap berlaku di Kedah dan kawasan yang bersempadan dengan Siam, Pulau Pinang dan Perak. Sebagai contoh, Sultan Abdul Hamid telah berhubung dengan Konsul Siam di Pulau Pinang mengenai aduan terhadap Jalaludin dan Omar yang menipu orang Perak pada tahun 1888. Pihak berkuasa Perak telah berusaha untuk memberkas mereka di samping memohon kerjasama daripada pihak Kedah bagi membantu usaha berkenaan. Pihak Kedah mendapati mereka tidak berada di Kedah dan berjaya melarikan diri ke Singgora. Walau bagaimanapun, pihak Kedah telah memberi jaminan akan menahan mereka sekiranya berjaya ditemui di negeri ini. ${ }^{34}$ Sultan Abdul Hamid juga pernah mengirimkan surat kepada pihak Siam mengenai aduan terhadap Lebai Mat yang menipu Haji Wan Abdullah dan Ludin mengenai pembayaran hasil tanah di Kerian pada tahun 1889. Tindakan Lebai Mat ini amat dikesali kerana beliau telah menjual tanah berkenaan kepada seorang individu berbangsa Cina bernama Khu Su. Pada masa yang sama, beliau telah menipu Haji Wan Abdullah supaya membayar hasil tanah kepadanya kononnya atas arahan Penghulu Haji Ali. Walau bagaimanapun, perbuatan beliau telah diampunkan. Malangnya, sekali lagi beliau mengulangi perbuatan tersebut dengan mengambil surat kecik tanah Ludin tanpa memulangkannya, sedangkan perbincangan mengenai status tanah berkenaan belum lagi selesai. Baginda telah mencadangkan kepada Konsul Siam supaya mengenakan hukuman yang setimpal terhadap Lebai Mat atas kesalahannya itu. ${ }^{35}$

Selain itu, perbuatan menipu turut dilakukan oleh individu tertentu yang kemudiannya melarikan diri ke Kedah. Hal ini sering dicatatkan dalam SMSAH. Dalam surat yang dihantar kepada pihak British di Pulau Pinang, Sultan Abdul Hamid telah menerima aduan mengenai perbuatan menipu barang-barang yang dilakukan oleh Haji Muhammad Yasin di Pulau Pinang dan waran menangkapnya telah dikeluarkan. Beliau telah berjaya ditahan oleh pihak Kedah dan 
kemudiannya diserahkan kepada pihak polis untuk dibicarakan di Pulau Pinang pada tahun $1893 .{ }^{36}$ Perbuatan jenayah seperti menipu turut dipandang serius oleh kerajaan Kedah kerana perbuatan ini jelas menimbulkan kesusahan hidup individu yang telah ditipu. Bagi menangani perbuatan menipu ini daripada berleluasa, kerajaan Kedah telah bekerjasama dengan pihak Siam dan British bagi menangkap penjenay ah yang berada di kawasan sempadan wilayah masing-masing semasa zaman pemerintahan Sultan Abdul Hamid.

\section{Perbuatan Melarikan Perempuan Tanpa Kebenaran}

Perbuatan melarikan perempuan sama ada anak dara, kanak-kanak atau isteri orang juga dikategorikan sebagai salah satu perbuatan jenayah yang dianggap serius oleh kerajaan Kedah. Wanita yang dilarikan itu bukan sahaja melibatkan kaum Melayu dan Cina malah turut membabitkan kaum India. Sekitar tahun 1880-an, banyak aduan mengenai perbuatan melarikan perempuan dicatatkan dalam SMSAH. Antara catatan berkenaan ialah sepucuk surat daripada Sultan Abdul Hamid kepada pihak British di Pulau Pinang mengenai perbuatan Mat Jawa melarikan seorang perempuan bernama Haminah, isteri kepada Dahaman, yang menetap di Sungai Daun ke Pulau Pinang berserta barang bernilai dan wang tunai pada tahun 1889. Aduan ke atas beliau telah dibuat oleh Dahaman dan pihak mahkamah telah mengeluarkan waran menangkap mereka. Merujuk isi kandungan surat dalam SMSAH, baginda telah memohon bantuan daripada pihak British untuk menangkap si penjenayah berkenaan. ${ }^{37}$ Begitu juga dengan sepucuk surat Sultan Abdul Hamid mengenai aduan terhadap Bakar yang melarikan anak Mat Arshad pada tahun 1893, ${ }^{38}$ Selain melarikan perempuan Melayu, perbuatan ini turut melibatkan perempuan berbangsa Cina. Sebagai contoh, aduan Lu Ah Yu dan Lee Ah Kee mengenai isterinya telah dilarikan oleh Wong Boon Fatt ke Kulim serta saudaranya yang dilarikan oleh Lee Ah Kin ke Relau yang dicatat dalam SMSAH. Baginda telah mengambil tindakan sewajarnya dengan mengarahkan pihak polis membuat operasi mencari seterusnya menangkap mereka pada tahun $1889 .{ }^{39}$

Surat Raja Muda kepada pihak British turut dikirimkan mengenai aduan seorang peniaga, Chang Eng terhadap Kasimsa yang telah melarikan anak perempuannya bersama-sama wang tunai ke Pulau Pinang. Si pengadu itu berusaha mencari dan berjaya menemui mereka di Kampung Melaka. Raja Muda telah menasihatkan Chang Eng supaya mengadu kepada pihak Residen Kaunselor untuk mendapatkan anak perempuannya itu dan berharap pihak British dapat menyelesaikan kes ini dengan kadar segera." Tunku Abdul Aziz juga ada mengirimkan 
surat kepada para pembesar negeri mengenai aduan tentang perbuatan melarikan perempuan ${ }^{41}$ dan memerintahkan agar tindakan tegas diambil bagi mengurangkan kegiatan ini daripada berleluasa di Kedah. Merujuk kepada sistem perundangan Islam, perbuatan melarikan perempuan bukan muhrim sama ada secara paksaan atau sukarela dianggap satu kesalahan berat yang menyebabkan institusi perkahwinan dan kekeluargaan menjadi rosak dan tercemar. Malah dalam undangundang yang diamalkan di Kedah, hukuman berat akan dikenakan kepada mereka yang melakukannya seperti mana yang terkandung dalam Kanun Al-Akubat 1335 H. $^{42}$ Tindakan tegas yang diambil oleh kerajaan Kedah ini bertujuan mengelakkan wanita yang dilarikan dari hidup sengsara di kemudian hari dan hal ini akan menyusahkan keluarga masing-masing kelak.

Perbuatan melarikan diri daripada melangsaikan hutang juga banyak dicatat dalam SMSAH. Sultan Abdul Hamid pernah mengirimkan surat kepada pihak Siam mengenai aduan tentang beberapa orang individu yang enggan membayar hutang. ${ }^{43}$ Sepucuk surat bertarikh 8 Julai 1891, turut dihantar kepada Konsul Siam di Pulau Pinang mengenai senarai aduan orang ramai di Balai Merbok, terhadap $\mathrm{Ku}$ Kiling yang telah melarikan diri daripada melangsaikan hutang kepada mereka berjumlah kira-kira $\$ 155.76$. Baginda telah menitahkan Penghulu Abdul Rahman dan Wan Yunus supaya menyiasat aduan berkenaan sebelum menahan si penghutang berkenaan untuk dibicarakan di Kedah. Semasa surat ini dikirimkan kepada Konsul Siam di Pulau Pinang bertarikh 8 Julai 1891, si penghutang ini masih belum ditemui dan tidak dapat dipastikan di mana beliau melarikan diri dan bersembunyi. Merujuk kepada SMSAH didapati, Sultan Abdul Hamid mengarahkan para pegawai Kedah menyiasat kes lari dari membayar hutang dan menangkap si penghutang kerana baginda tidak mahu si penghutang lari dari tanggungjawab melangsaikan hutang. Malah, tindakan ini dapat mengelak si pemiutang dari menanggung kerugian dari pembuatan si penghutang yang lari dari membayar wang yang dipinjamkan. ${ }^{44}$

Terdapat beberapa pucuk surat perjanjian antara majikan dengan para pekerjanya, berserta jumlah hutang turut dicatatkan dalam SMSAH yang dikirimkan kepada Sultan Abdul Hamid dan Sir Truter Acting, Residen Kaunselor British di Pulau Pinang. Surat penjanjian itu turut mencatatkan tentang beberapa orang pekerja yang melarikan diri dan tidak melangsaikan hutang mereka kepada Ku Teng Lee. ${ }^{45}$ Terdapat juga laporan mengenai beberapa pekerja kebun buahbuahan milik Tuan Brown berbangsa India di Prai telah melarikan diri ke Kuala Muda. Walau bagaimanapun, sultan tidak mengambil tindakan tegas kerana mereka bukanlah banduan yang melarikan diri. 
Sebaliknya, baginda menyarankan agar mereka berunding secara baik dengan majikan berkaitan dengan pembayaran hutang sebelum ini. ${ }^{40}$ Jika ditinjau dari sudut sejarah, golongan yang berhutang yang tidak mampu membayarnya dikehendaki bekerja dan tinggal dengan pihak pemiutang sehingga hutang selesai dilunaskan atau akan terus menjadi hamba kepada mereka termasuklah isteri dan anak-anak. Malah mereka juga boleh dijual. ${ }^{47}$ Perkara ini menyebabkan Majlis Mesyuarat Negeri Kedah mengeluarkan arahan bahawa sebarang urusan berkaitan dengan hutang perlu didaftarkan dengan kerajaan negeri supaya tidak timbul unsur penindasan dan penipuan pada masa akan datang. ${ }^{4 s}$

\section{Pergaduhan Berkumpulan}

Pergaduhan berkumpulan merupakan satu perbuatan jenayah yang berbahaya dan sering mengancam keselamatan dan menganggu ketenteraman awam. Antara maklumat yang terkand ung dalam SMSAH berkaitan dengan pergaduhan berkumpulan ialah beberapa pucuk surat daripada Sultan Abdul Hamid kepada pihak Perak melalui Raja Muda Yusof dan Residen British mengenai pergaduhan antara orang Rawa dengan orang Bilah yang berlaku di kawasan Kedah. Pergaduhan ini berpunca daripada perlanggaran perahu antara kedua-dua pihak. Pergaduhan berkenaan agak serius sehingga memaksa baginda memohon bantuan daripada kerajaan Perak pada Disember 1882 untuk membawa pilhak yang terlibat ke muka pengadilan di Kedah. ${ }^{49}$

Selain itu, baginda ada mengutuskan surat kepada Biayaly Janton, seorang saudagar yang rapat dengan baginda bersama-sama dengan Penghulu Abdul Rahman untuk pergi meninjau Karangan di Kulim, lokasi berlakunya pergaduhan yang berpunca daripada perebutan untuk menguasai laluan air lombong. ${ }^{50}$ Pergaduhan yang berlaku di Karangan begitu serius dan melibatkan kumpulan-kumpulan Cina yang mengusahakan kegiatan perlombongan di sana. Bagi menyelesaikan pergaduhan berkenaan, baginda telah mengarahkan Penghulu Abdul Rahman mengerahkan penduduk tempatan ke Karangan untuk menahan mereka yang terlibat dalam pergaduhan berkenaan. Kejadian pergaduhan yang melibatkan orang Cina di Kedah turut berlaku di Pulau Langkawi. ${ }^{51}$ Isu perebutan hak mengutip hasil pajakan timah sering berlaku di antara kumpulan-kumpulan Cina sehingga mencetuskan pergad uhan berdarah seperti mana yang berlaku di Kulim pada $1888 .{ }^{52}$

Merujuk maklumat dalam SMSAH, kerajaan Kedah begitu mengambil berat mengenai kejadian pergaduhan dan bertindak tegas kepada sesiapa yang terlibat seperti mana yang berlaku di Sungai Petani pada tahun 1899. Sultan Abdul Hamid telah mengarahkan pegawai di 
daerah berkenaan menyiasat dan seterusnya menahan mereka yang disyaki terlibat. ${ }^{53}$ Terdapat juga peristiwa pergaduhan antara Tuan Ledeborgh, peniaga dari Belanda dengan Penghulu Mukim Kupang dan penduduk setempat mengenai perebutan tanah di Sedim. Walau bagaimanapun, masalah berkenaan dapat diselesaikan oleh kerajaan Kedah. Perkara yang ditonjolkan dalam SMSAH ini menunjukkan pejabat Sultan memang memainkan peranan penting dalam mengawal hal-ehwal dalaman negeri Kedah termasuk tindakan menangani masalah pergaduhan tanpa perlu campur tangan daripada pihak British dan Siam. ${ }^{54}$

\section{Pembabitan Golongan Pentadbir dalam Kes Jenayah}

Agak menarik, perbuatan jenayah yang sering berlaku di Kedah sekitar akhir kurun ke-19 dan awal kurun ke-20 dipercayai turut membabitkan golongan pentadbir peringkat mukim dan kampung khususnya individu yang bergelar penghulu. ${ }^{55}$ Penghulu yang terlibat selalunya bertindak sebagai penaung dan pelindung kepada gerakan penjenayah berkenaan. Malah tuan tanah yang kaya dan ketua kampung turut terlibat dalam perbuatan berkenaan. Kewujudan kerjasama antara ketua kampung dan penghulu di kawasan sempadan Kedah-PerlisSiam dapat dikesan dalam kegiatan jenayah seperti mencuri binatang ternakan. Golongan ini bertanggungjawab dalam urusan pendaftaran lesen, pertukaran nama dan proses jual-beli termasuklah perbuatan menyembelih binatang berkenaan. ${ }^{56}$

Sekitar tahun 1890-an, beberapa orang penghulu di Kedah didapati terlibat dalam kegiatan jenayah itu telah dihukum dengan pemecatan daripada jawatannya dan turut dibuang negeri, contohnya Nai Sim dan Nik Man Nik Taha (penghulu mukim Guar Kepayang). ${ }^{57}$ Keadaan ini sering menimbulkan masalah kepada pihak polis yang berusaha membanteras kegiatan jenayah di Kedah ketika itu sedangkan penduduk setempat pula tidak mahu memberikan kerjasama kerana takut dengan pengaruh pihak penghulu yang akan bertindak ganas dan bimbang menjadi sasaran balas dendam penjenayah terhadap mereka kelak. Selain itu, penduduk setempat juga memikirkan perjalanan jauh yang terpaksa ditempuhi sekiranya dipanggil memberi keterangan di mahkamah. Masalah ini turut menarik perhatian kerajaan Kedah dalam usaha menangani perbuatan jenayah. Kerajaan Kedah telah mengambil tindakan menguatkuasakan undang-undang dan memberi perlindungan keselamatan kepada para penduduk yang menjadi saksi dalam satu-satu kes perbicaraan. ${ }^{58}$

Kegiatan jenayah yang berleluasa di kawasan pedalaman Kedah ini berpunca daripada masalah sosioekonomi kawasan sekitarnya yang 
kekurangan sumber dan lokasi kawasan berkenaan yang bersempadan dengan Siam yang turut mengalami permasalahan yang sama. ${ }^{59}$ Kawalan keselamatan dan penguatkuasaan undang-undang yang longgar ekoran masalah kekurangan balai polis dan anggota yang terhad turut menyebabkan kegiatan jenayah ini tidak dapat dibendung dengan baik..$^{60}$ Pembabitan orang Sam-Sam ${ }^{61}$ dalan kegiatan jenayah sering menjadikan daerah bersempadan dengan Siam seperti Kubang Pasu, Padang Terap, Sik dan Baling sebagai pusat gerakan dan lokasi persembunyian mereka dari ditangkap oleh pihak berkuasa. ${ }^{62}$

Penglibatan rakyat jelata dalam kegiatan jenayah ini juga berkait rapat dengan kesan yang dibawa oleh sistem ekonomi kapitalis yang memaksa mereka membayar pelbagai cukai yang kadangkalanya tidak mampu dibayar. Sebagai tanda protes, segelintir rakyat yang terdesak telah bertindak melakukan kegiatan jenayah seperti menyamun, pecah rumah, menculik orang-orang atasan seperti tuan tanalh yang kaya, peladang Eropah, peniaga Cina dan pemimpin tempatan. ${ }^{63}$ Perbuatan ini berkait rapat dengan perkembangan sosioekonomi Kedah semasa zaman pemerintahan Sultan Abdul Hamid yang telah mewujudkan jurang kekayaan yang ketara antara golongan kaya dengan miskin.

\section{Usaha Kerajaan Kedah Membanteras Jenayah}

Walaupun ada penghulu yang terlibat dengan kegiatan jenayah, namun masih ramai penghulu yang masih menumpahkan taat setia kepada kerajaan dan telah bertindak menangani kegiatan jenayah dengan menjalinkan kerjasama dengan pihak berkuasa serta menjaga kebajikan dan keselamatan anak buah mereka daripada ancaman penjenayah. Sebagaimana yang dapat dikesan dalam SMSAH di antara penghulu Kedah yang banyak berjasa kepada Kedah dalam usaha membasmi kegiatan jenayah seperti Penghulu Abdul Rahman di Kuala Muda, Penghulu Ismail di Merbok dan Penghulu Haji Ali di Kerian. ${ }^{64}$ Hakikatnya, penghulu diakui berperanan penting dalam menjaga keamanan mukim dan memastikan para penduduk di bawahnya terus setia kepada pemerintah. Walaupun kedudukan sosial golongan ini dipandang tinggi oleh masyarakat setempat tetapi masih ada di antara mereka yang mengkhianati amanah pemerintah dengan melibatkan diri dengan kegiatan jenayah demi keuntungan sendiri. Justeru itu, pihak kerajaan telah memberikan perhatian kepada golongan ini dan sekiranya ada dalam kalangan penghulu yang melanggar perintah akan dipecat, ditangkap dan dihukum. ${ }^{65}$

Pada dasarnya, kegiatan jenayah ini sebenarnya tidak mendapat sokongan daripada penduduk Kedah khususnya yang beragama Islam. 
Ini dibuktikan dengan penyertaan mereka dalam penubuhan Jam'iatul Ittihadiyah (Perhimpunan Bersatu) yang berperanan sebagai satu pakatan menentang kumpulan yang terlibat dengan jenayah. ${ }^{66}$ Perhatian yang serius oleh kerajaan Kedah dalam usaha membasmi masalah jenayah yang berleluasa sebenarnya banyak bergantung kepada kerjasama daripada para pembesar tempatan dan kesetiaan rakyat kepada Sultan Abdul Hamid. Maklumat ini ditemui dalam SMSAH yang secara tidak langsung menunjukkan wujud sistem pentadbiran yang cekap di bawah pemerintahan Sultan Abdul Hamid, dengan dibantu oleh para pembesar tempatan dan sokongan padu rakyat jelata dalam usaha membasmi kegiatan jenayah di Kedah. ${ }^{67}$

Sekiranya ada penghulu mukim yang bertinclak zalim dan tidak adil, anak buah akan mengadu kepada pemerintah Kedah melalui surat teriak. ${ }^{68}$ Kerajaan Kedah juga telah menguatkuasakan undang-undang yang telah diluluskan oleh Majlis Mesyuarat Negeri bagi membolehkan tindakan tegas dikenakan kepada mana-mana pertubuhan yang tidak mendaftar dan mempunyai ahli seramai 10 orang ke atas atau terlibat dengan kegiatan kongsi gelap. Sebagaimana yang tercatat dalam SMSAH, tindakan tegas yang diambil termasuklah hukuman penjara selama tiga tahun bersama-sama dengan kerja berat. ${ }^{69}$ Tindakan tegas ini membuktikan kerajaan Kedah mengambil berat terhadap kegiatan jenayah dan berusaha menangani masalah ini dengan menguatkuasakan undang-undang. Malah, kerajaan Kedah juga turut menjalin kerjasama dengan pihak British sejak tahun 1791 dan Siam dalam urusan kawalan keselamatan di kawasan sempadan masing-masing. ${ }^{70}$

Bagi mewujudkan keamanan dan pencegahan jenayah di Kedah, Sultan Abdul Hamid telah meminta bantuan Frank Swettenham bagi mengemas kini pasukan polis dengan pengambilan pegawai Eropah dan polis Sikh. ${ }^{71}$ Pada peringkat awal, mereka telah ditempatkan di Kulim seterusnya Alor Setar dan Kuala Muda. Pasukan anggota polis Sikh berjumlah 50 orang kemudiannya bertambah kepada 154 orang pada tahun 1905 di bawah pimpinan W.H. Mitchell manakala polis Melayu berjumlah 311 orang di bawah seliaan Wan Ismail Wan Hassan. Jawatan Inspektor Jeneral Polis Kedah dipegang oleh Tunku Bahadur Syah Tunku Dhiauddin pada tahun 1899.72 Pasukan polis Kedah turut dibantu oleh penghulu dan panglima mukim bagi menegakkan undangundang bagi membasmi masalah jenayah seterusnya menjamin kuasa pemerintah ke atas rakyat. Maklumat penting mengenai kesalahan jenayah di Kedah dan tindakan membasminya semasa zaman pemerintahan Sultan Abdul Hamid sering dicatat dalam SMSAH dan turut dilaporkan dalam sumber-sumber pihak British seperti KAR. 


\section{Kesimpulan}

Berdasarkan kepada catatan SMSAH dapat dirumuskan bahawa pada zaman pemerintahan Sultan Abdul Hamid, Kedah sering mengalami permasalahan sosial yang ketara membabitkan perbuatan jenayah berbanding zaman pemerintahan sebelumnya. Perbuatan ini seperti samun, penipuan, pembunuhan dan mencederakan individu, melarikan perempuan tanpa kebenaran, pergaduhan dan pembabitan golongan pentadbir dalam jenayah telah mengganggu ketenteraman awam malah turut membantutkan perkembangan ekonomi dan kestabilan politik Kedah. Maklumat ini sering dicatat dalam SMSAH dan disokong dengan KAR. Sultan Abdul Hamid dengan dibantu para pembesar negeri telah berusaha mengurangkan kadar jenayah ini dengan mengambil tindakan menguatkuasakan undang-undang, bekerjasama dengan pihak British dan Siam dan membentuk pasukan polis. Perkara ini membuktikan bahawa institusi kesultanan Melayu yang disokong oleh para pembesar tempatan telah memainkan peranan penting dalam menyelesaikan permasalahan sosial seperti perbuatan jenayah.

Selepas kemangkatan Sultan Abdul Hamid pada tahun 1943, takhta Kedah dipegang oleh Sultan BadliShah. Ketika itu, pentadbiran dikuasai oleh pihak Jepun yang berjaya mengalahkan pihak Bersekutu yang terdiri daripada British, Belanda, Perancis, Rusia dan Amerika Syarikat. SMSAH telah mengalami kerosakan kesan tidak dijaga dengan baik di Balai Besar. Segala maklumat mengenai kegiatan jenayah y ang berlaku di Kedah telah diuruskan oleh pihak Jepun manakala Pejabat Sultan Kedah hanya mengendalikan urusan agama Islam dan masyarakat Melayu. Selepas Perang Dunia Kedua berakhir pada tahun 1945, pihak British kembali ke Tanah Melayu meneruskan tindakan campur tangan dalam urusan pentadbiran Kedah hingga menyebabkan Pejabat Sultan semakin kurang berfungsi.

\section{Nota}

Tunku Fariduddin Tuanku Mansor, Titisan Kerabat: Buku Cenderamata Merdeka 31 Ogos, Bukit Mertajam: Eastern Printers, 1957, hlm. 18.

2 Mat Kassim Majid, "Sultan Abdul Hamid Halim Shah: Pengasas Kedah Moden", Kedah Dari Segi Sejarah, Jilid 9, No. 11, November 1981, hIm 1-5. Ibrahim Ismail, t.t.p., "Zaman Pemerintahan Sultan Ahmad Tajuddin Mukaram Shah ( $1270 \mathrm{H}-1296 \mathrm{H}$ bersanaan 1854M-1879M) dan Zaman Pemerintahan Sultan Abdul Hamid Halim Shah (1882M-1943M)", Artikel untuk Muzium Negeri, Alor Setar: Lembaga Muzium Negeri Kedah, hlm. 1-12.

4 Temuramah dengan Dato' Dr. Haji Wan Shamsuddin Mohd Yusof, Pengerusi Persatuan Sejarah Malaysia cawangan Kedah/Perlis di Muzium Negeri Kedah, ALor Setar pada 21 Jun 2010. 
5 Sharom Ahmat, Kedah-Tradition and Change in Malay State: A Study Economic and Political Development: 1778-1923, MBRAS, Monograph No. 1, 1984, hlm. 5. Cheah Boon Kheng, The Peasant Robber of Kedah: Historical and Folk Perceptions. Singapore: Oxford University Press, 2001, hlm. 53.

- SMSAH No. 2, Surat Sultan Abdul Hamid kepada Phrak Surin Teramat Kaluan pada 5 Jamadilawal 1305H/19 Januari 1888M, hlm. 58.

7 Ibid., Surat Sultan Abdul Hamid kepada Phya Surapon Pipit pada 21 Muharam 1308H/6 September 1890M, hlm. 366 .

\& SMSAH No. 3, Surat Sultan Abdul Hamid kepada Konsul Siam di Pulau Pinang pada 24 November 1882 dan 23 Safar $1300 \mathrm{H} / 3$ Januari $1883 \mathrm{M}$, hlm. 22- 23 dan 28-29.

9 SMSAH No. 2, Surat Sultan Abdul Hamid kepada Raja Singgora pada 21 Rabiulakhir 1306H/25 Disember 1888M dan 27 Rejab 1307H/19 Mac 1890M, hlm. 142-143, 248-249 dan 251.

10. Ibid., Surat Phaya Wichana Kiri negeri Singgora kepada Sultan Abdu Hamid pada 11 Rabiulawal 1312H/11 September 1894M, hlm. 506-512.

11 SUK/K, No. Fail $1767 / 1344$

$12 \quad S U K / K$, No. Fail 473/1345.

13 Mahani Musa, Kongsi Gelap Melayu di Negeri-negeri Utara Pantai Barat Semenanjung Tanah Melayu: 1821 hingga 1940-an. MBRAS: Monograph No. 36, 2003, hlm. 141-144.

$14 \mathrm{CO} 275$, Sesional Papers: Report of the Administration of the Straits Settlements, 1860-1866 dipetik daripada Mahani Musa, Kongsi Gelap Melay di Negeri-negeri Utara Pantai Barat Semenanjung Tanah Melayu: 1821 hingga 1940-an, hlm. 143.

15 SMSAHNo. 2, Surat Sultan Abdul Hamid kepada Raja Singgora bertarikh 22 Zulkaedah $1302 \mathrm{H} / 2$ September $1885 \mathrm{M}$.

16 lbid., Surat Sultan Abdul Hamid kepada Phya Sontra Norak pada 22 Rabiulakhir 1308H/5 Disember 1890M, hlm. 273-274.

1 SMSAH No. 3, Surat Sultan Abdul Hamid kepada Raja Singgora pada 8 Jawadilakhir 1306H / 9 Februari 1889, hlm. 149-150. SMSAHNo.2, contoh salinan pas memasuki Singgora, hlm. 345 .

18 CO 716, September 1906-Februari 1908, hlm. 11.

19 Cheah Boon Kheng. The Peasant Robber of Kedah: Historical and Folk Perceptions, hlm. 72-75. Rujuk Mohd. Isa Othman, Pengalaman Kedah dan Perlis Zaman Penjajahan British, Kuala Lumpur: Utusan Publications \& Distributors., 2001, hlm. 307-308.

20 SMSAH No. 3, Surat Sultan Abdul Hamid kepada Residen Kaunselor British di Pulau Pinang pada 22 Syaaban $1299 \mathrm{H} / 15$ Julai $1882 \mathrm{M}$.

2 Ibid., Surat Sultan Abdul Hamid kepada Residen British di Perak pada 26 Jamadilawal 1307H/18 Januari 1890M, hlm. 184.

22 Ibid., Surat Sultan Abdul Hamid kepada Raja Muda Perak, Raja Yusof pada 13 Syaaban $1299 \mathrm{H} / 28$ Julai $1882 \mathrm{M}$, hlm. 8 .

23. Ibid., Surat Sultan Abdul Hamid kepada Raja Muda Perak pada 13Syaaban $1299 \mathrm{H} / 29$ Julai $1882 \mathrm{M}, \mathrm{hlm} .9$.

24 SMSAHNo. 5, Surat Sultan Abdul Hamid kepada Konsul Siam, 18 Syawal $1308 \mathrm{H} / 27$ Mei $1891 \mathrm{M}$. 
25 Ibid., Surat Sultan Abdul Hamid kepada Residen British di Perak pada 21. Rabiulawal 1311H/2 Oktober 1893M, hlm. 321.

26. SMSAH No. 2, Surat Sultan Abdul Hamid kepada Tan Chukun Semuchi Rat Kaluang pada 8 Jamadilakhir 1310H/ 28 Disember $1892 \mathrm{M}$, hlm. 443444.

27 Ibid., Surat Sultan Abdul Hamid kepada Phrak Norak Yuta Kaluang pada 17 Rabiulakhir 1306H/21 Disember 1888M, hIm. 141.

28 SMSAH No. 8, Surat Haji Wan Abdullah kepada Penghulu Abdul Rahman pada 9 Safar $1316 \mathrm{H} / 29$ Jun $1898 \mathrm{M}$.

29 Ibid., Surat Raja Muda Kedah kepada Penghulu Abdul Rahman pada 15 Rabiulakhir 1317H/22 Ogos 1899M.

30 Tunku Abdul Aziz menjadi Raja Muda Kedah dari tahun 1885-1896 kemudiannya menjadi Pemangku Sultan Kedah. Baginda mangkat pada 13 Mei 1907.

31 SMSAHNo.5, Surat Tunku Abdul Aziz, Raja Muda Kedah kepada Residen Kaunselor British di Pulau Pinang, 6Syaaban 1309H/6 Mac 1892M, hlm. 167.

32 SMSAH No. 8, Surat Che Mohd Ariffin Kerani kepada Wan Yahya Wan Mohd Taib, 25 Muharam 1319H/14 Mei 1901M, hlm. 108.

33 Ismail Haji Salleh, Negeri Kedah di Zaman Pembaharuan, Penodenan dan Pembangunan, Alor Setar: Arkib Negara Malaysia cawangan Utara, t.t.p., hlm. 7.

34 SMSAHNo. 3, Surat Sultan Abdul Hamid kepada Konsul Siam di Pulau Pinang pada 18 Zulkaedah $1305 \mathrm{H} / 28$ Julai $1888 \mathrm{M}$.

35 Ibid., bertarikh 9 Syaaban $1306 \mathrm{H} / 10$ April $1889 \mathrm{M}$.

36. Ibid., bertarikh 28 Jamadilakhir $1310 \mathrm{H} / 17$ Januari $1893 \mathrm{M}$.

3 SMSAH No. 3, Surat Sultan Abdul Hamid kepada Residen Kaunselor British di Pulau Pinang pada 17 Syawal $1306 \mathrm{H} / 16$ Jun $1889 \mathrm{M}$.

38 SMSAH No. 8, bertarikh 10 Rabiulawal 1311H/21 September $1893 \mathrm{M}$.

${ }^{39} \quad$ Ibid., bertarikh 29 Zulkaedah $1306 \mathrm{H} / 28$ Julai $1889 \mathrm{M}$.

40 SMSAH No. 5, Surat Raja Muda Kedah kepada Tuan Skinner, Residen Kaunselor British di Pulau Pinang pada 2 Muharam 1311H/16 Julai $1893 \mathrm{M}$.

4SMSAHNo. 8, Surat Raja Muda Kedah kepada Penghulu Abdul Rahman, Kuala Muda dan Tunku Muhammad Saad, Kulim bertarikh 23 Zulkaedah $1316 \mathrm{H} / 4$ April $1899 \mathrm{M}$ dan 10 Rabiulawal $1317 \mathrm{H} / 18$ Julai $1899 \mathrm{M}$.

42 Kanun Al-Ankubat. SMSAH No. 11, Undang-Undang Penjual dan Pembeli Getah dan Bijih. T.H.1335H/1916M.

43 SMSAH NO. 2, Surat Sultan Abdul Hamid kepada Phya Sontra Norak pada 12 Rabiulakhir 1308H/25 November $1890 \mathrm{M}$, hlm 269.

44 SMSAHNo. 5, Surat Sultan Abdul Hamid kepada Konsul Siam di Pulau Pinang bertarikh 1 Zulkaedah 1308H/8 Julai 1891M.

4. Ibid., Surat Penjanjian Kuli-Kuli Cina Ku Teng Lee Kebun Kulim bertarikh 19 Jun 1891.

4h lbid., Surat Sultan Abdul Hamid kepada Residen Kaunselor British di Pulau Pinang bertarikh 26 \& 29 Safar $1310 \mathrm{H} / 18$ \& 21 September $1892 \mathrm{M}$. 
47 Aminuddin Baki, "The Institution of Debt-Slavery in Perak", Peninjan Sejarih, Jil. 1, Vol. 1, Julai 1966, hlm. 1-11.

48 MMNK (Majlis Mesyuarat Negeri Kedal), Debt Bondage Enactment No. 9 of 1328AH, 8 Julai 1910.

49 SMSAH No. 3. Surat Sultan Abdul Hamid kepada Raja Muda Perak bertarikh 6 Safar 1300H/17 Disember 1882M.

50. Ibid., Surat Sultan Abdul Hamid kepada Biayaly Janton dan Baba Lee Centuan bertarikh 25 Zulkaedah dan 8 Jamadilakhir 1306 H/ 24 Julai dan 9 Februari $1889 \mathrm{M}$.

51 Ibid., Surat Sultan Abdul Hamid kepada Residen Kaunselor British di Palau Pinang bertarikh 13 Jamadilakhir $1307 \mathrm{H} / 3$ Februari $1890 \mathrm{M}$.

52 SMSAH No. 10, Surat Che Mohd Ariffin kepada Raja Muda Kedah bertarikh 20 Zulkaedah $1323 \mathrm{H} / 16$ Januari $1906 \mathrm{M}$.

53. SMSAH No. 8, Surat Haji Wan Abdullah kepada Penghulu Abdul Rahman bertarikh 13 Syawal 1317H/13 Februari 1900M.

54 SMSAH No. 10, Surat Che Mohd Ariffin Kerani kepada Tunku Mahmud, Presiden Majlis Mesyuarat Negeri Kedah bertarikh 18 Jamadilawal $1325 \mathrm{H} / 29$ Jun $1907 \mathrm{M}$.

55 CO 716, Kedah Annual Report, Sept. 1905-Ogos 1908, hlm. 12.

56 Ibid., hlm. 8.

57 Rujuk SUK Kedah 1805/1339 bertarikh 5 Mac 1921.

58. Mahani Musa, Kongsi Gelap Melayu di Negeri-negeri Lhara Pantai Barat Semenanjung Tanah Melayu: 1821 hingga 1940-an, hlm. 144.

59 Cheah Boon Keng, The Peasant Robber of Kedah: Historical and Folk Perceptions, hIm. 18-19

60 Cheah Boon Kheng, "Jenayah-Jenayah di Sempadan Kedah-Siam di antara Tahun 1900-1920-an", dalam Konvensyen Sejarah Negeri Kedah, Alor Setar: Wisma Negeri, 28 November-1 Disember $198 \mathrm{I}$, hlm. 8.

6 Orang Sam-sam adalah orang Siam yang menetap di Kedah menganggap diri mereka sebagai orang Melayu-Islam yang berkebolehan berbahasa Siam. Kawasan penempatan utama mereka di daerah yang bersempadan dengan Siam seperti Kubang Pasu, Sik, Padang Terap. Rujuk Mohd. Isa Othman, Pengalanan Kedah \& Peris, hIm. 31.

-2 Mahani Musa, Kongsi Gelap Melayu di Negeri-negeri Utara Pantai Barat Semenanjung Tanah Melayu: 1821 lingga 1940-an, hlm. 148.

63 Mohd. Isa Othman, Pengalanan Kedah dan Perlis Zantan Petijajahan British, hlm. 308 .

64 SMSAH No. 3, Surat Sultan Abdul Hamid kepada Konsul Siam di Pulau Pinang pada 25 Muharam $1306 \mathrm{H} / 1$ Oktober $1888 \mathrm{M}$.

65 SUK Kedal 1805/1339 bertarikh 5 Mac 1921.

66 Ismail Haji Salleh, "Haji Wan Ibrahim bin Wan Abd. Kadir (1892-1968)", Biografi Ulama Kedah Darul Aman, Alor Setar: Muzium Negeri Kedah, Jilid 1, 1996. hlin. 187.

6.) SMSAH No. 2, 3, 5, \&\&10

68 Sharom Ahmat, Kedah-Tradition and Change in Malay State: A Study Economic and Political Developntent: 1778-1923, hlm. 84. 
69 SMSAH No. 13, 1338H/1919, Undang-undang yang diluluskan oleh MMNK berkenaan dengan hukuman terhadap kegiatan kongsi gelap dan pertubuhan haram.

70 R. Bonney, Kedah 1771-1821: The Search for Security and Independence, Kuala Lumpur: Oxford University Press, 1971, hlm. 186, appendix 4 (c).

71 F.O. 422/30, Swettenham kepada The Government of Straits Settlement, 6 November 1899.

:2 Ahmad Tajuddin Yahya, "Sejarah Ringkas Pasukan Polis Negeri Kedah", Kedah Dari Segi Sejarah, 1976, Jilid 5, No. 1, hlm. 32-33. 